\title{
Managing Tilted Molar Abutment Using a Digitally Fabricated Split-Pontic Fixed Dental Prosthesis-A Case Report
}

\author{
Pronoy Mukhopadhyay, Arun Khalikar, Sattyam Wankhade, Suryakant Deogade \\ Department of Prosthodontics, Government Dental College \& Hospital, Nagpur, India \\ Email: pronoy.mukherjee@yahoo.com
}

How to cite this paper: Mukhopadhyay, P., Khalikar, A., Wankhade, S. and Deogade, S. (2021) Managing Tilted Molar Abutment Using a Digitally Fabricated Split-Pontic Fixed Dental Prosthesis-A Case Report. Open Journal of Stomatology, 11, 311-316. https://doi.org/10.4236/ojst.2021.118027

Received: July 21, 2021

Accepted: August 21, 2021

Published: August 24, 2021

Copyright $\odot 2021$ by author(s) and Scientific Research Publishing Inc. This work is licensed under the Creative Commons Attribution International License (CC BY 4.0).

http://creativecommons.org/licenses/by/4.0/

\begin{abstract}
Prosthetic rehabilitation of a missing tooth with tilted abutments is yet an enigmatic and less unconventionally sought-after treatment strategy. Many methods have been previously reviewed over the years. This clinical report aims to integrate the principles of the segmented fixed dental prosthesis into a digital workflow. It elucidates the rehabilitation using a split-pontic design that mitigates the issue of developing a common path of insertion without much compromise to the tooth preparation to derive parallel prepared walls. This prosthetic design rather incorporates a common path of insertion into the pontic in the form of a key-keyway non-rigid connector design.
\end{abstract}

\section{Keywords}

Split-Pontic, Tilted Molar, Non-Rigid Connector, CAD/CAM

\section{Introduction}

A missing tooth complicates the oro-facial dynamics leading to various compensatory mechanisms that lead to enigmatic circumstances for prosthetic rehabilitation, especially when done after a prolonged delay [1]. One such issue is the drifting of the adjacent teeth to mitigate the prosthetic space. This leads to the abutment teeth tipping into an angular-assumed position for which accentuated tooth preparation is required to facilitate an aligned path for placing the fixed prosthesis with rigid connectors [2]. Over the years, various strategies have been documented in the literature to deal with such a dire situation, such as orthodontic up-righting of the tipped abutment [3], mesial-half crown retainers [1] and non-rigid connector systems [4]. This article demonstrates a case report where tilted abutments were managed using a segmented fixed dental prosthesis fabricated us- 
ing digital subtractive manufacturing technology.

\section{Clinical Report}

A 33-year-old female patient reported to the Department of Prosthodontics, with the chief complain of difficulty in chewing from the left side. On examining the patient, it was found that she was missing a left mandibular $1^{\text {st }}$ molar tooth (Figure 1). On further interview, she elaborated a history of extraction of the left mandibular first molar, approximately 5 years back which she did not get replaced due to some personal problems. Diagnostic impressions were made and articulated on a mean-value articulator for occlusal evaluation (Figure 2). The distal abutment (left mandibular second molar) showed a mesially-tipped angulation while the mesial abutment was upright. On radiographic evaluation, no pathology was

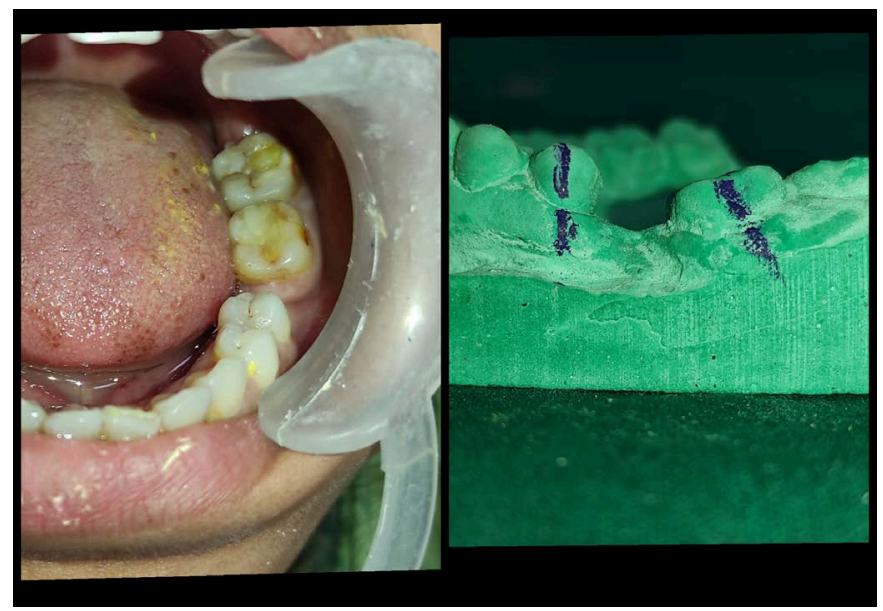

Figure 1. Pre-operative evaluation demonstrates missing left mandibular $1^{\text {st }}$ molar with the distal abutment tipped into the pontic space.

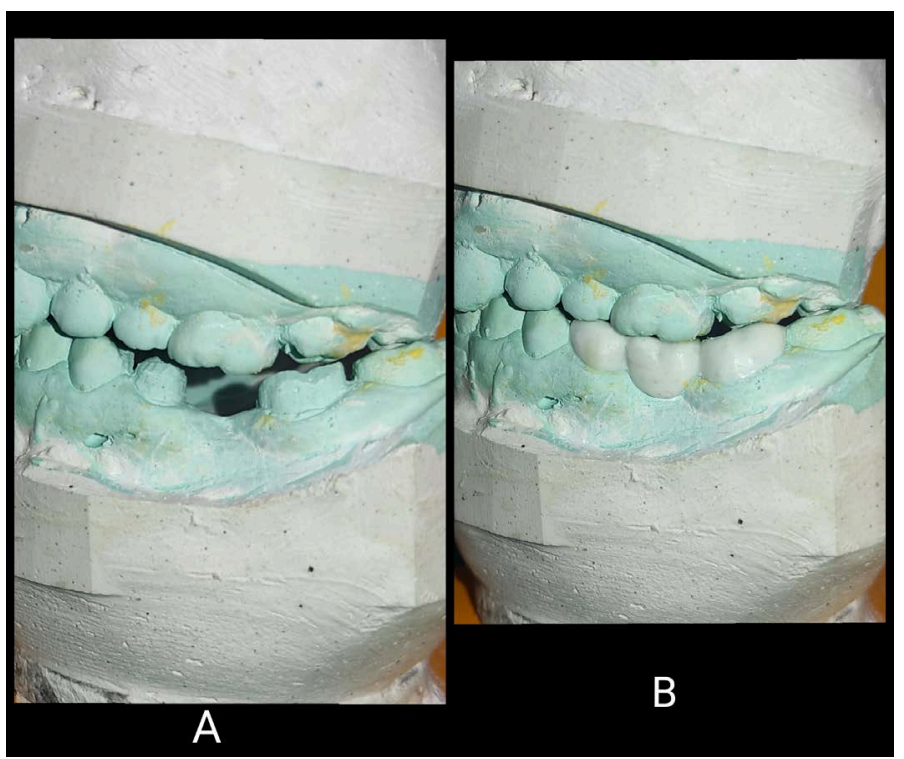

Figure 2. (A) Diagnostic mock preparation done on mounted casts; (B) Diagnostic wax-up done. 
observed in the mesial abutment while a composite restoration within the confines of the Dentino-Enamel Junction was observed in the distal abutment. The treatment strategy planned was that of a 3-unit fixed dental prosthesis with a split-pontic design.

\section{Treatment Procedure}

A mock preparation and diagnostic wax-up was done on the diagnostic cast and a silicone index was obtained (Figure 3). Under adequate local anaesthesia, tooth preparation was done to provide sufficient occlusal and axial clearance for a Porcelain-fused-to-Metal prosthesis with a shoulder margin provided throughout except lingually where a chamfer margin was prepared. The preparation was done to preserve the axis of the abutments without compromising much tooth structure to derive any parallelism.

After adequate gingival retraction (SureCord \#000), a one-stage putty-wash impression was made using Addition Silicone impression material (Elite, Zhermack) was made (Figure 4). Using the silicone index of the wax-up, chairside temporaries were fabricated using Bis-Acryl composite (CoolTemp, Coltene) and temporarily cemented using eugenol-free temporary luting cement (GC Freegenol). The casts were then individually scanned using a laboratory scanner (Identica

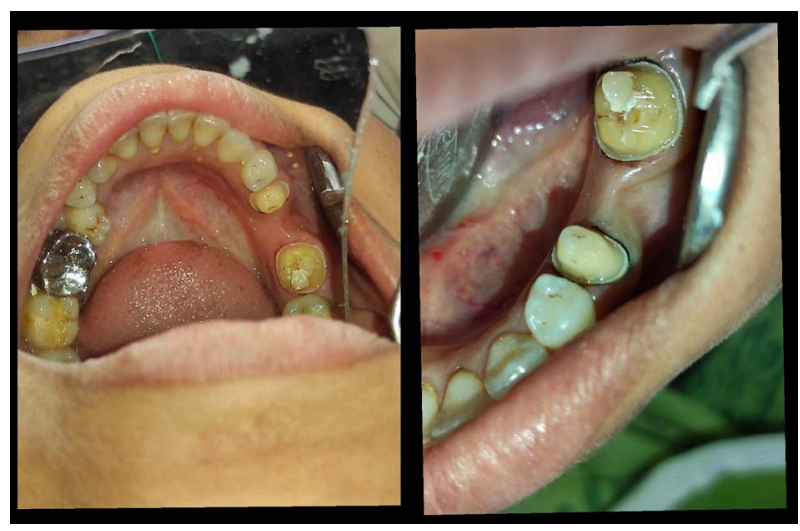

Figure 3. Tooth preparation done providing shoulder margin all over except lingual aspect where chamfer was provided and gingival retraction performed using impregnated retraction cord.

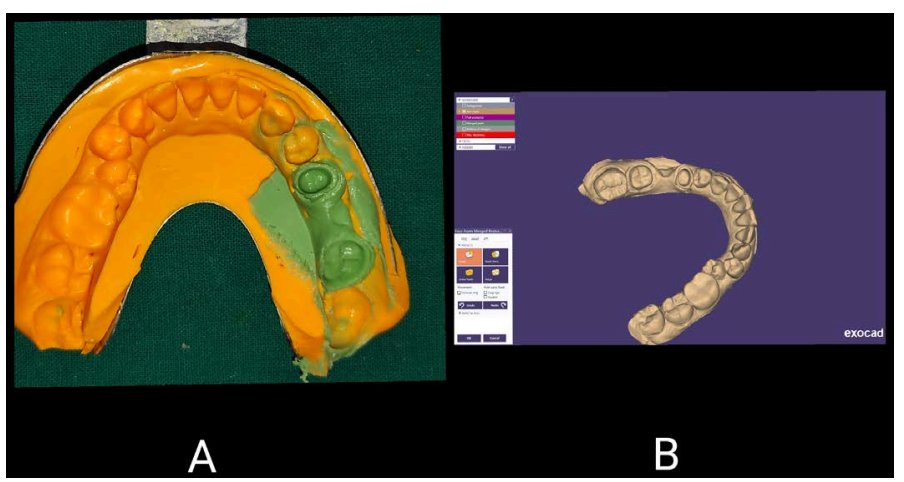

Figure 4. (A) Addition silicone impression; (B) Scanned cast. 
Hybrid; MEDIT corp., Korea) and then transferred to a design software (exocad Dental CAD; exocad GmbH, Germany) in occlusion (Figure 4).

The pattern for the mesial retainer was first designed with a male extension provide distal to it, parallel to the long axis of the premolar. Then the pattern for the distal retainer was designed maintaining the long axis of the molar and pontic incorporating a female key-way that is oriented along the path of the premolar male extension (Figure 5). A resin pattern of the prosthesis was milled and tried intra-orally to check the fit. Once the fit was found to be satisfactory, the patterns were milled (Arum 5-axis Wet and Dry Milling Machine, Doo Won) in metal and cut back to provide space for ceramic veneering (Figure 6). Porcelain of a matched shade was then veneered and sintered on to the metal coping. The prosthesis was tried intra-orally for any necessary occlusal adjustments and then glazed to final polish. The prosthesis was cemented (Figure 7) in two phases with male using Type I Glass Ionomer Cement (GC Gold Label 1). First the mesial retainer

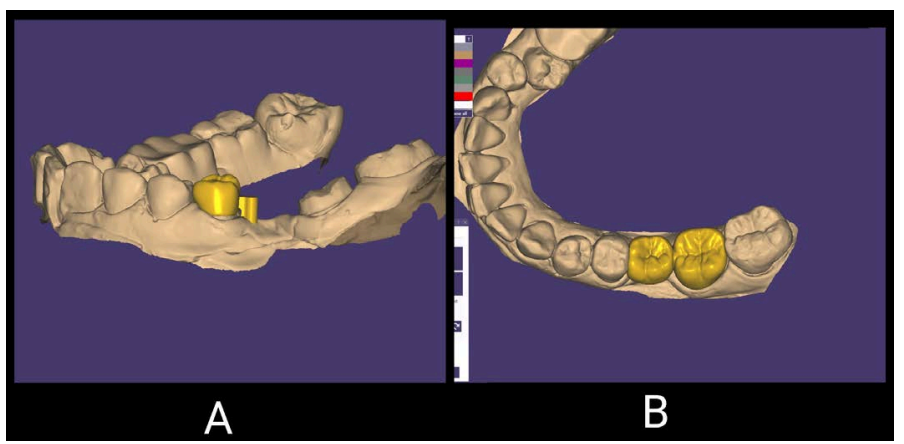

Figure 5. CAD-CAM design of prosthesis in design software (exocad Dental CAD; exocad $\mathrm{GmbH}$, Germany) with surveyed path of insertion incorporated in split pontic design.

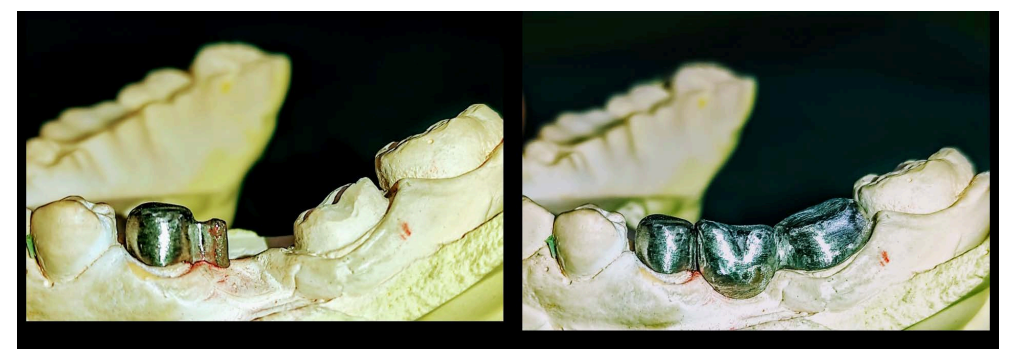

Figure 6. Metal Trial of individual components.

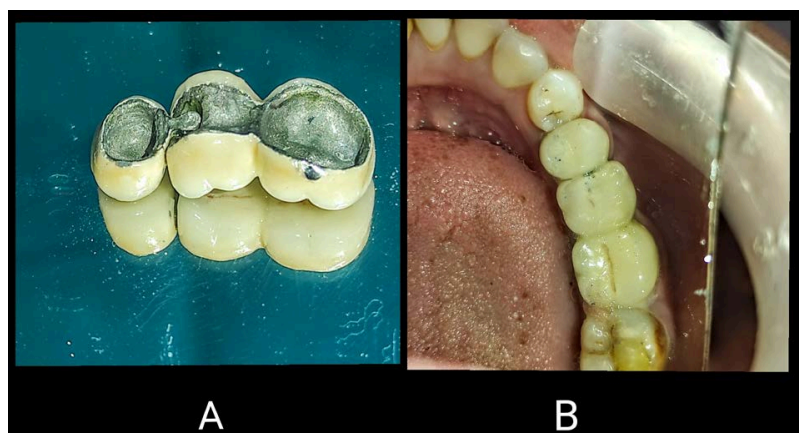

Figure 7. (A) Final Porcelain-fused-to-metal prosthesis; (B) Prosthesis cemented in place. 
with male extension is luted followed by the distal retainer and the pontic. Patient was then given post-cementation instructions and followed up after $24 \mathrm{hrs}$ and 7 days. On follow-up, the patient expressed comfort in chewing from both sides and no issues of food lodgment as well.

\section{Discussion}

The path of insertion for a prosthesis can be defined as an imaginary line, in the direction of which a restoration can either be placed or removed [1]. In order for the prosthesis to smoothly seat onto the prepared teeth, the walls of the preparation must all be oriented parallel to each other. Mesio-distal inclination of the preparation, if inclined, causes the restoration to be held up at the proximal region at the area of contact with the adjacent tooth [1]. Connectors that provide for a limited range of movement between independent components of a fixed dental prosthesis are referred to as Non-Rigid Connectors. A split pontic is a non-rigid connector design that facilitates placement of a fixed prosthesis without any compromise in the tooth preparation [5]. It involves designing one-half of the pontic incorporated in either retainer and deriving a parallelism through a key-keyway mechanism designed under the pontic.

Usually, split pontic connectors are designed by custom-milling machines of pre-fabricated inserts. This report demonstrates a CAD-designed split pontic connector which mitigates additional armamentarium for surveying and precisely positioning the connector components in perfect alignment. The software with an in-built surveyor precisely positions the connector and designs the receptacle into the pontic without any intervening human error. Additionally, the split pontic design provides a "safety-valve" cushioning mechanism for the connectors of nonparallel abutments by allowing some rotation and resiliency in the split area [6]. This procedure even saves the tooth from unwarranted endodontic procedures that would otherwise be required in order to derive parallel walls of either abutment. The digital workflow ensures adequate precision in orienting the non-rigid connector system without any distortion involved in casting the pattern. The particular design used in this case report ensures an aesthetically pleasing and periodontally healthy rehabilitative approach.

\section{Conclusion}

A segmented fixed dental prosthesis provides a very practical solution for mis-aligned abutments. The incorporation of a non-rigid connector in the form of a splitpontic design provides for a periodontally favorable prosthetic strategy. The keykeyway mechanism even prevents unprecedented metal show which is thus, an aesthetically pleasing alternative as well.

\section{Conflicts of Interest}

Authors would like to declare that there are no conflicts of interests in publishing this content. 


\section{References}

[1] Shillingburg, H.T., Sather, D.A., Wilson, E.L., Cain, J.R., Mitchell, D.L., Blanco, L.J., et al. (2012) Fundamentals of Fixed Prosthodontics. 4th Edition, Quintessence Publishing Co. Inc., Chicago, 81-96.

[2] Rosenstiel, S., Land, M. and Fujimoto, J. (2016) Contemporary Fixed Prosthodontics. 5th Edition, Mosby Inc., St. Louis, 70-92.

[3] Lubow, R.M., Cootey, R.L. and Kaiser, D. (1982) Periodontal and Restorative Aspects of Molar Uprighting. The Journal of Prosthetic Dentistry, 47, 373-376. https://doi.org/10.1016/S0022-3913(82)80083-8

[4] Zuckerman, G.R. (1996) Planning Fixed Partial Dentures for Severely Misaligned Abutments. Quintessence International, 27, 527-532.

[5] O'Connor, R.P., Caughman, W.F. and Bemis, C. (1986) Use of the Split Pontic Non-rigid Connector with the Tilted Molar Abutment. The Journal of Prosthetic Dentistry, 56, 249-251. https://doi.org/10.1016/0022-3913(86)90484-1

[6] Beleidy, M. and Ziada, A. (2020) Fracture Resistance Evaluation of CAD/CAM Monolithic Zirconia FDPs with Different Split Pontic Designs Restoring Tilted Molar Abutments. Egyptian Dental Journal, 66, 1351-1361. https://doi.org/10.21608/edj.2020.24002.1015 